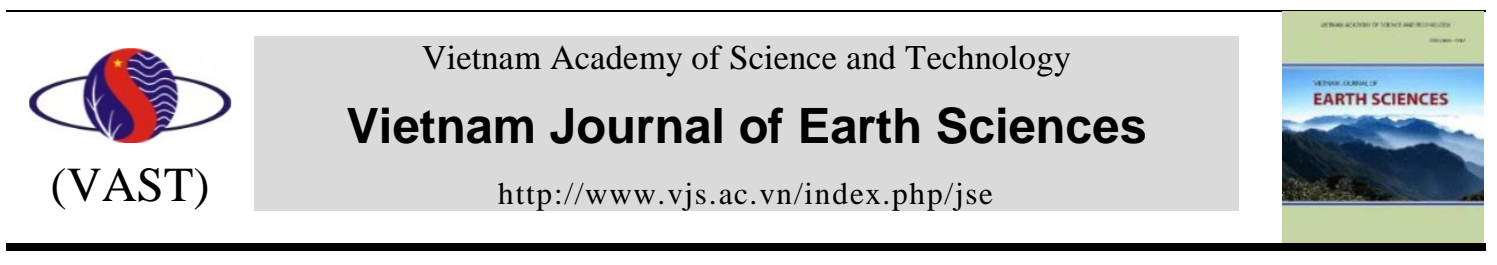

\title{
Development of a Web-GIS based Decision Support System for earthquake warning service in Vietnam
}

\author{
Nguyen Hong Phuong1, 2, 3*, Nguyen Ta Nam¹, Pham The Truyen ${ }^{1,2}$ \\ ${ }^{1}$ Institute of Geophysics (VAST), Hanoi, Vietnam \\ ${ }^{2}$ Graduate University of Science and Technology(VAST), Hanoi, Vietnam \\ ${ }^{3} I R D$, Sorbonne Universités, UPMC Univ Paris 06, Unité Mixte Internationale de Modélisation Mathé- \\ matique et Informatiques des Systèmes Complexes (UMMISCO)32 venue Henri Varagnat, 93143 Bondy \\ Cedex, France
}

Received 03 February 2018; Received in revised form 09 April 2018; Accepted 30 May 2018

\begin{abstract}
This paper describes the development of a Decision support system (DSS) for earthquake warning service in Vietnam using Web GIS technology. The system consists of two main components: (1) an on-line database of earthquakes recorded from the national seismic network of Vietnam, and (2) a set of tools for rapid seismic hazard assessment. Using an on-line earthquake database, the system allows creating a shake map caused by a newly recorded earthquake. In addition, the Web GIS environment allows any user, including non-professional to get useful information about a just-occurred event and the possible impact caused by the earthquake shortly after its occurrence. A fault-source model developed for Vietnam was used as a part of the hazard calculation and mapping procedure. All information and results obtained from the system are automatically included in the earthquake bulletins, which will be disseminate national wide afterward by the Vietnam earthquake information and tsunami warning Center.

The shake maps produced by the DSS in terms of both Peak Ground Acceleration and intensity values are rapidly available via the Web and can be used for emergency response, public information, loss estimation, earthquake planning, and post-earthquake engineering and scientific analyses. Application of the on-line decision support system in earthquake warning service can mitigate the earthquake risk and reduce the losses and damages due to earthquakes in Vietnam in future.
\end{abstract}

Keywords: Web-GIS; decision support system; earthquake hazard; RARE.

(C)2018 Vietnam Academy of Science and Technology

\section{Introduction}

Earthquakes cause the damages on the Earth's surface. The severity of damage in terms of casualties and loss of properties caused by an earthquake in the region near epicenter greatly depends on its focal depth and

*Corresponding author, Email: phuong.dongdat@gmail.com magnitude. Despite of the fact that prediction of earthquake occurrence time is inherently impossible, the fast detection and early warning of an earthquake's parameters can help considerably to reduce the casualties and losses in the epicenter region.

The Institute of Geophysics (IGP) within the Vietnam Academy of Science and Technology (VAST) is operating the national 
seismic network and has been given the responsibility for issuing earthquake information throughout the territory of Vietnam and adjacent sea areas in order to reduce the impact of this natural disaster. For earthquake detection, the waveforms recorded from the seismic stations throughout the country are displayed on the large screens of the Earthquake Information and Tsunami Warning Center at IGP. Seconds or minutes after occurrence of an earthquake, its main parameters such as the occurrence time, coordinates of epicenter, focal depth and magnitude are defined both manually and automatically by specialized software. As the time for saving lives and properties after earthquakes is counted in minutes, it is important to reduce the time of earthquake data processing from the moment of earthquake detection to the moment of issuing warning. The most common information available immediately following damaging earthquakes are traditionally their magnitude and epicenter location. However, the damage pattern is not a simple function of these two parameters alone, and more detailed information is required to properly evaluate the situation.

This paper describes the development of a Decision Support System (DSS) for earthquake warning service in Vietnam. The two main functions of the system include Rapid Assessment of Real-time Earthquakes (RARE) and issuing earthquake bulletins. The DSS aims to enhance the capability of the national earthquake warning service in order to mitigate and reduce the earthquake risk in the entire territory of Vietnam and adjacent sea areas.

\section{Technology basis}

To develop the Decision Support System for on-line earthquake warning, a Web-GIS technology has been applied, using the open source programs and libraries that widely provided in the internet. The interface of the Decision Support System for on-line earthquake warning (below referred as DSS), which was designed on the basis of HTML, CSS and the PHP programming language, was used for in- teraction between users and a PostgreSQL database. The system's most important GIS component is displayed in the form of a map containing three main layers namely the base map of the study area covering the whole territory of Vietnam and the East Vietnam sea; the seismically active faults systems in the study area, and epicenters of earthquakes instrumentally recorded in the study area.

The DSS's map layers, created by the Mapserver, Openlayer and PostGIS applications, providing a flexible and effective environment for users to work with spatial data. In addition, some other functions have been developed to enhance the DSS's security and efficiency as the user permission or the switch between Vietnamese and English languages. All programs are working in the Window environment to ensure the compatibility and stability of the system. Working in the Web environment, the DSS can be used by any user with access to the internet and with such popular web browsers as Firefox, Chrome, Knock Knock, etc.

Figure 1 illustrates the DSS's user interface as it will be linked to the website of the Institute of Geophysics (IGP). The upper part shows logo and address of the Earthquake Information and Tsunami Warning Center, IGP. The upper right buttons allow users to log in the system and choose working language. The tabs in the lower part of the display can be used for accessing to different components of the system. From left to right, the names and contents of the tabs are described below.

(i) The "Homepage" tab contains the introductory information about the Earthquake Information and Tsunami Warning Center, IGP.

(ii) The "Earthquake Bulletins" allows to display the bulletins of the most recent earthquakes, issued by the Earthquake Information and Tsunami Warning Center, IGP.

(iii) The "Seismicity map" tab gives access to a seismicity map, showing distribution of epicenters of the most recent earthquakes, instrumentally recorded in the territory of Vietnam and adjacent sea areas. 
(iv) The "Earthquake Database" tab gives access to a database of the most recent earthquakes recorded in in the territory of Vietnam and adjacent sea areas. The database is regularly updated at the IGP.

(v) The "Earthquake Hazard" tab provides a toolset for rapid assessment of realtime earthquakes (RARE), which can be used for calculating and displaying a shake map caused by a rea-time earthquake. The hazard information taken from the shake map then will be automatically added into the earthquake bulletin.

To fulfill earthquake warning task, the most important role in the DSS play the online earthquake database and the toolset for rapid assessment of seismic hazard from a real-time earthquake.
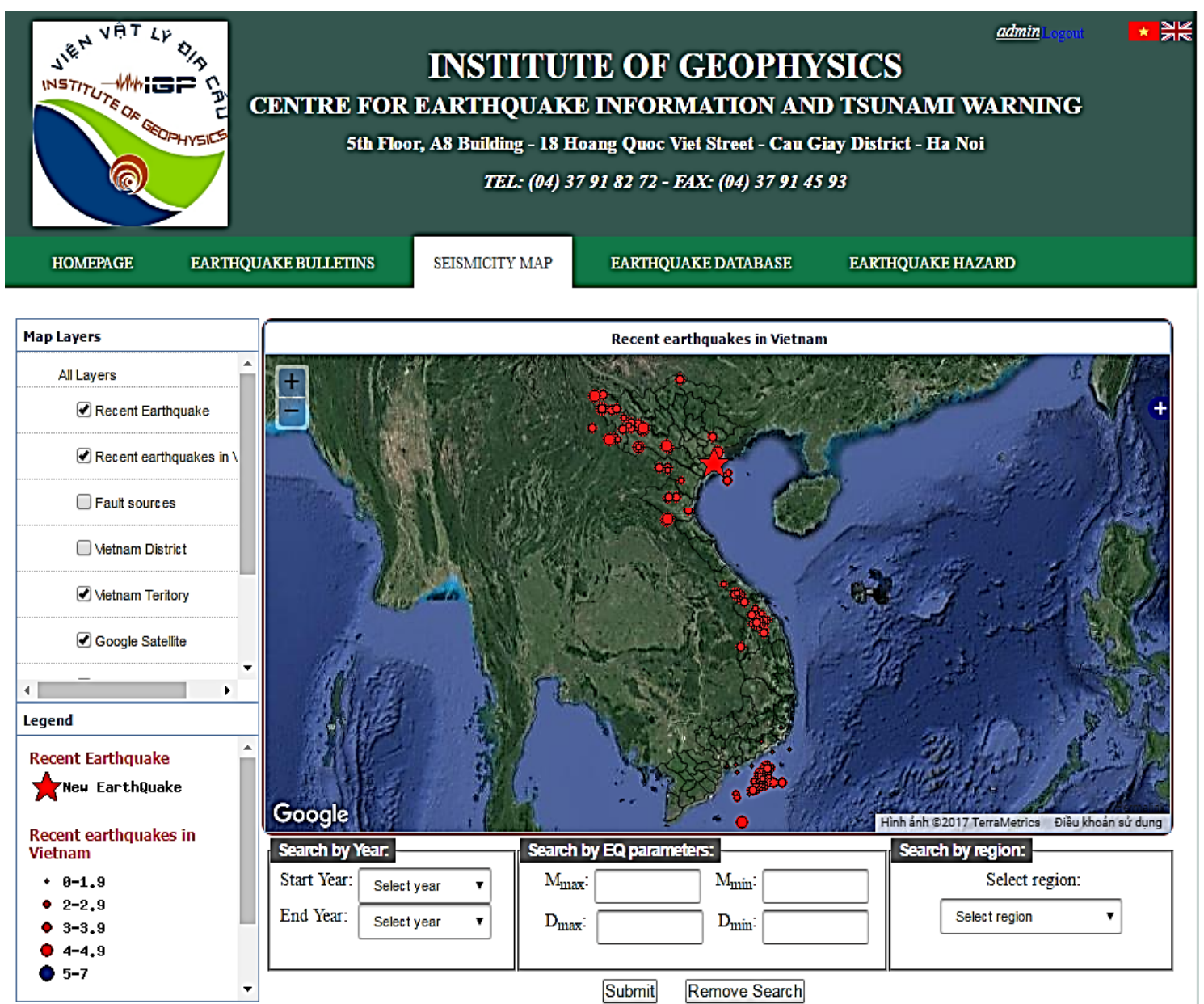

Figure 1. User interface of the Decision Support System for on-line earthquake warning

\section{On-line database of recent earthquakes in Vietnam}

An on-line database is designed and included into the DSS to store the most recent earthquakes occurred in the territory of Vietnam and the adjacent sea areas. All of these events were recorded by the national and local seismic networks of Vietnam, operated by the Institute of Geophysics. The parameters of all recorded earthquakes are informed in the IGP website and in the earthquake bulletins issued and disseminated national wide by IGP in case if the magnitude 
exceeds M3.5. The users can access to work with the on-line database of earthquakes in Vietnam by clicking on one of the "Seismicity map" and "Earthquake database" tabs in the DSS's interface.

After clicking on the "Seismicity map" tab, a map showing distribution of epicenters of the earthquakes, being stored in the on-line database will appear (Figure 1). On the map, the epicenter of the last recorded earthquake is denoted by a big star to distinguish with the others, which are denoted by the circles. The sizes of the circles are proportional to the magnitudes of earthquakes they represent. The seismicity map gives a visualization of contemporary seismic activity in the territory of Vietnam and adjacent sea area. The users can click on each epicenter on the map to query the parameters of the event, such as occurrence time, epicenter's coordinates, the focal depth, magnitude and the name of the place where earthquake occurred. The users can also retrieve and display the issued bulletin of each event. In addition, the tools located at the lower part of the interface allow searching earthquakes from the on-line database according to such various criteria as magnitude, depth, year of occurrence and place name. The sought data, which satisfies the sort criteria, will be displayed on the map.

The "Earthquake database" tab gives access to the on-line database of recent earthquakes in Vietnam. Here, the users can browse a catalog of the most recent earthquakes and work with the database by several manipulations such as update, edit, and delete events (Figure 2). Figure 3 illustrates a tool for inputting the parameters of a newly recorded earthquake into database. Once the user has input the earthquake parameters and clicked "Submit" button, a message will appear asking the user to confirm the location of the new earthquake before it will be stored in the database. As the new earthquake is added into the catalog, its epicenter will also appear on the seismicity map (see Figure 1).

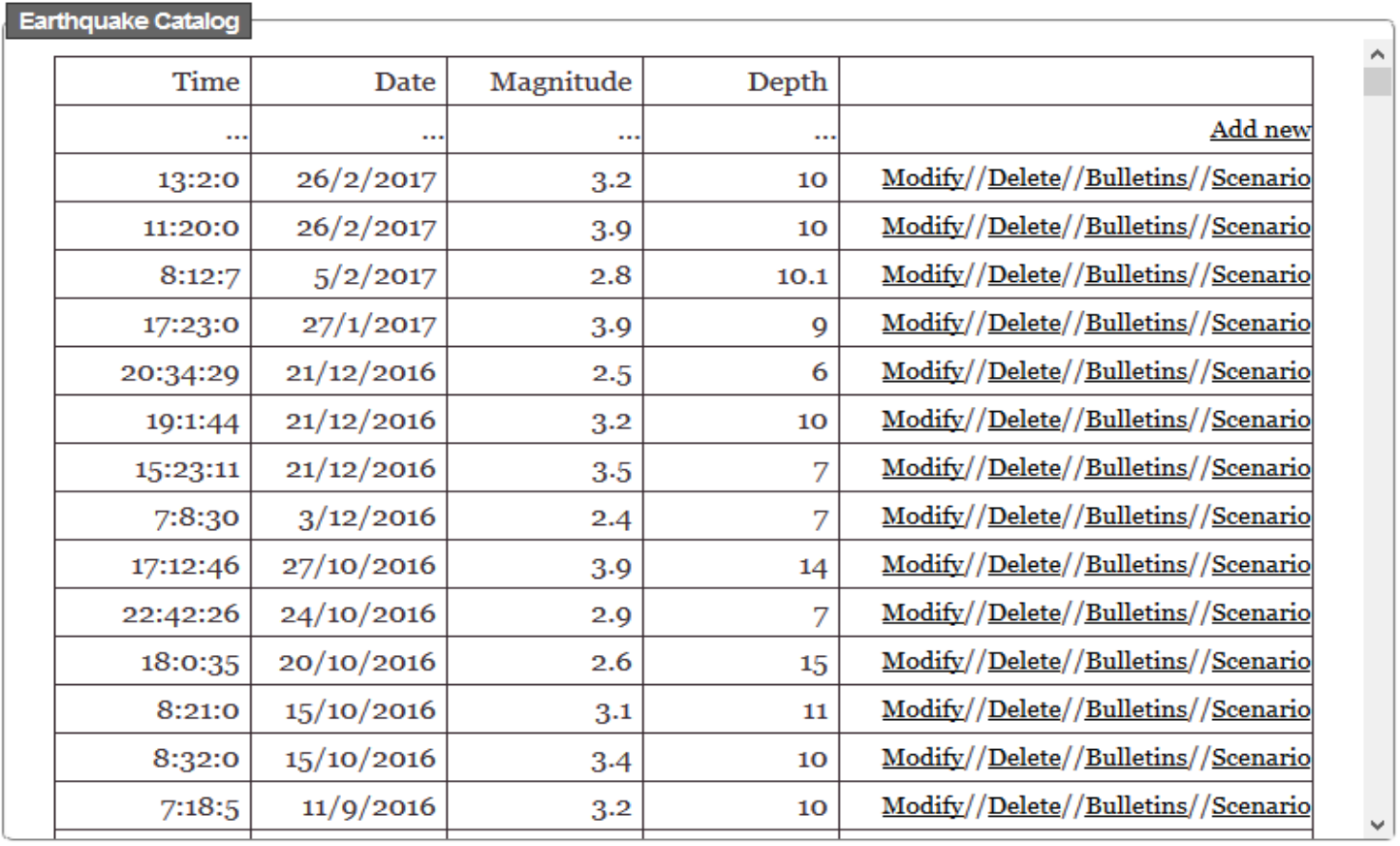

Figure 2. Catalog of earthquakes, stored in the on-line database of recent earthquakes in Vietnam 


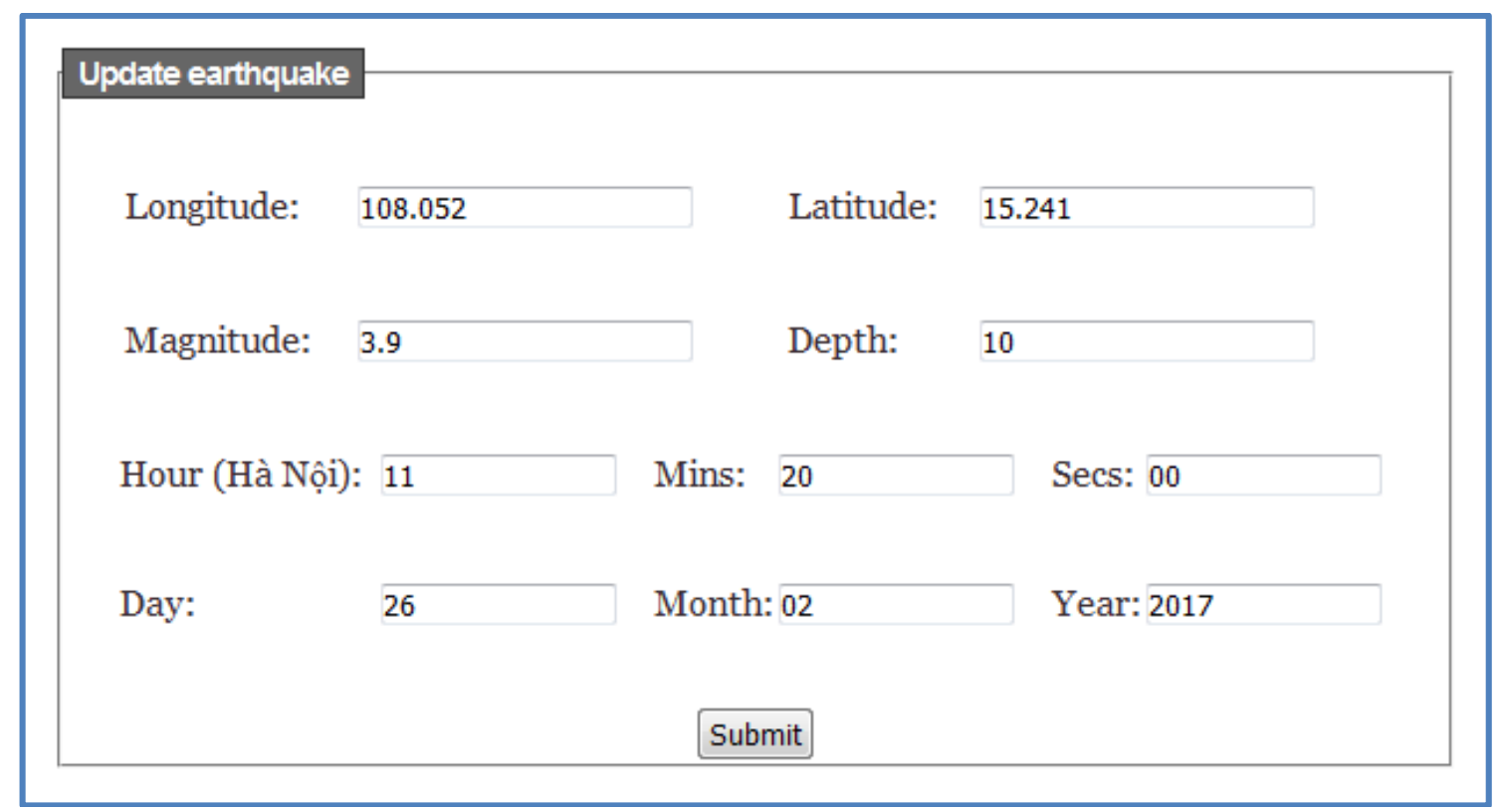

Figure 3. Input window for updating a new earthquake into the on-line database

The most important function of the on-line earthquakes database is to provide input parameters for the rapid assessment of a real time earthquake tool (RARE). The development and application of the RARE will be described in details in the following paragraphs of the paper.

\section{Development of an on-line tool for sce- nario based seismic hazard assessment}

\subsection{Seismic source modeling}

The quantitative seismic hazard assessment is usually based on pre-developed source models, which simulate the process of energy release and seismic wave propagation of an earthquake from source to site. The seismic hazard models allow to calculate hazard at a given point and then to construct the hazard map for the entire study area.

Such seismic hazard models were first developed and used by Cornell (1968) and Milne and Davenport (1969). In these models, it is assumed that the total energy released by earthquakes radiated from the focus of the earthquake, and therefore may be called "point-source models". The application of the point-source models would not be accurate in case of major earthquakes, when total energy released is distributed along the rupture zone that could be several tens or hundreds kilometers long or when the site is located very close to the fault. In general, the rupture length is a significant parameter in the determination of seismic hazard, and neglecting its effect would tend to underestimate the real risk to large-magnitude earthquakes. To overcome the disadvantages of point-source models, Der Kiureghian and Ang (1977) at the same time with Douglas and Ryall (1977), proposed a fault-source model, which is based on the assumption that an earthquake originates at the focus and propagates as an intermittent series of fault ruptures or slips in the rupture zone of the Earth's crust, and that the maximum intensity of ground shaking at a site is determined by the slip that is closest to the site. However, the modeling of seismic sources has only become effective with application of GIS technology. 
In Vietnam, GIS technology has been applied in deterministic seismic hazard assessment since beginning of the $21^{\text {st }}$ century. With assumption that an earthquake originates on a rupture of an active fault, a fault source model was developed for Vietnam using a database of 46 seismically active fault systems in the territory of Vietnam and adjacent sea area (Bui Van Duan et al., 2017). The fault systems are grouped in two ranks, depending on their depth of active layers and magnitude thresholds and digitized in a GIS environment, then linked with their attribute data. There are two types of fault attribute data stored in the database. The first type is the descriptive information, including fault name, fault rank, type of faulting, main direction, total length, etc. More important attribute type is the fault parameters, which can be used directly to the hazard calculation as maximum moment magnitude, surface and subsurface rupture sizes, fault plan solutions, etc.

For each fault system, the Wells and Coppersmith (1994) empirical relationship between earthquake magnitude $M$ and rupture length $\mathrm{L}$ has been applied:

$$
\log _{10}(\mathrm{~L})=\mathrm{a}+\mathrm{b}^{*} \mathrm{M}
$$

where $L$ is the rupture length $(\mathrm{km})$ and $M$ is the moment magnitude of the earthquake; $a$ and $b$ are regression coefficients, determined for different types of faults and given in Table 1.

Table 1. Regression coefficients of fault rupture relationship of Wells and Coppersmith (1994)

\begin{tabular}{|c|c|c|c|}
\hline Rupture type & Fault type & $\mathrm{a}$ & b \\
\hline \multirow{3}{*}{ Surface } & Strike slip & $-3,55$ & 0,74 \\
\hline & Reverse & $-2,86$ & 0,63 \\
\hline & All & $-3,22$ & 0,69 \\
\hline \multirow{3}{*}{ Subsurface } & Strike slip & $-2,57$ & 0,62 \\
\hline & Reverse & $-2,42$ & 0,58 \\
\hline & All & $-2,44$ & 0,59 \\
\hline
\end{tabular}

\subsection{Attenuation models}

When an earthquake occurs, the energy radiates from the source will impact the Earth's surface in terms of ground shaking. Relation- ship between the ground motion parameters $\mathrm{Y}$, the earthquake magnitude $\mathrm{M}$ and the focal distance $\mathrm{R}$, also known as the attenuation equation, can be express as follows:

$$
Y=c_{1} \exp \left(c_{2} M\right) R^{c_{3}}
$$

where $\mathrm{Y}$ is one of the peak ground motion values (acceleration, velocity, or displacement), $c_{1}, c_{2}$ and $c_{3}$ are spatial dependent constants. In case of a fault source, $\mathrm{R}$ indicates the distance from fault to site.

The establishment of an attenuation equation to be applied for a study region is important and usually considered as a separate stage in the whole seismic hazard assessment procedure. Vietnam, however, as many other low-seismicity countries of the World, is always facing the problem in developing an attenuation law aplicable for the country. Although several large earthquakes have occurred within the territory of Vietnam, there were no strong ground motion data available for the country untill the year 2000, where the first strong ground motion record of the country was obtained from a M5.0 event. Due to the lack of strong ground motion data of the strong earthquakes, for a long time no local attenuation equations have been developed for Vietnam.

There have been attempts to develop attenuation equations for Vietnam. Xuyen and Thanh (1999) proposed an empirical equation developed from the isoseismal maps, collected during field investigations of different earthquakes in Vietnam. However, the reliability of this equation is questionable as the field investigation data does not reflect the direct relationship between earthquake magnitude and the ground shaking parameters. In 2011, two groups of authors independently published the attenuation equations developed for Vietnam (Minh et al., 2012, Tran and Kiyomiya, 2012). However, for the first study, the earthquake data used has been collected within a small area in North Vietnam and all of them have medium magnitudes (Minh et al., 2012), while 
for the latter, the earthquake data used is not representative for the territory of Vietnam (Tran and Kiyomiya, 2012). Therefore, these two attenuation equations are still in the process of verification untill now.

\subsection{Development of a desktop GIS tool: F-Hazard}

The first application of the Vietnam's fault source model is called "F-Hazard" with a function of seismic hazard assessment from a scenario earthquake assumed to be originated by a tectonic fault. The software was designed in the desktop GIS environment, playing role of a DSS that allows automatic implementation of various stages in a seismic hazard assessment procedure, such as selection of study region and active fault, definition of a scenario earthquake, and hazard calculation and mapping of seismic shaking distribution.

Figure 4 illustrates the calculation procedure of the F-Hazard tool. As it can be seen from the figure, this is a five steps procedure, resulting in the ground shaking maps for the study area. The procedure starts with definition of a study area. Then follows the selection of a fault from GIS database, which is capable of generating an earthquake in the selected area. The fault parameters are used to describe a source of the scenario earthquake assumed to be originated on the chosen fault. Then, a proper attenuation equation is chosen for computation of seismic hazard of the study area, according to the given scenario. Two ground motion parameters are used to express seismic hazard. The first parameter is Peak Ground Acceleration (PGA), in units of g, and the other one is shaking intensity I, characterizing the strength of shaking on the earth's surface, reported on non-instrumental MSK64 scale. In results, a shake map of the study area in terms of PGA and I values is automatically displayed. The relationship between the values of PGA and intensity $\mathrm{I}$ is given in Table 2. The conversion is not implemented in the cases, when I is less than level V and I exceeds level $\mathrm{X}$, for there is no practical meaning in engineering seismology.

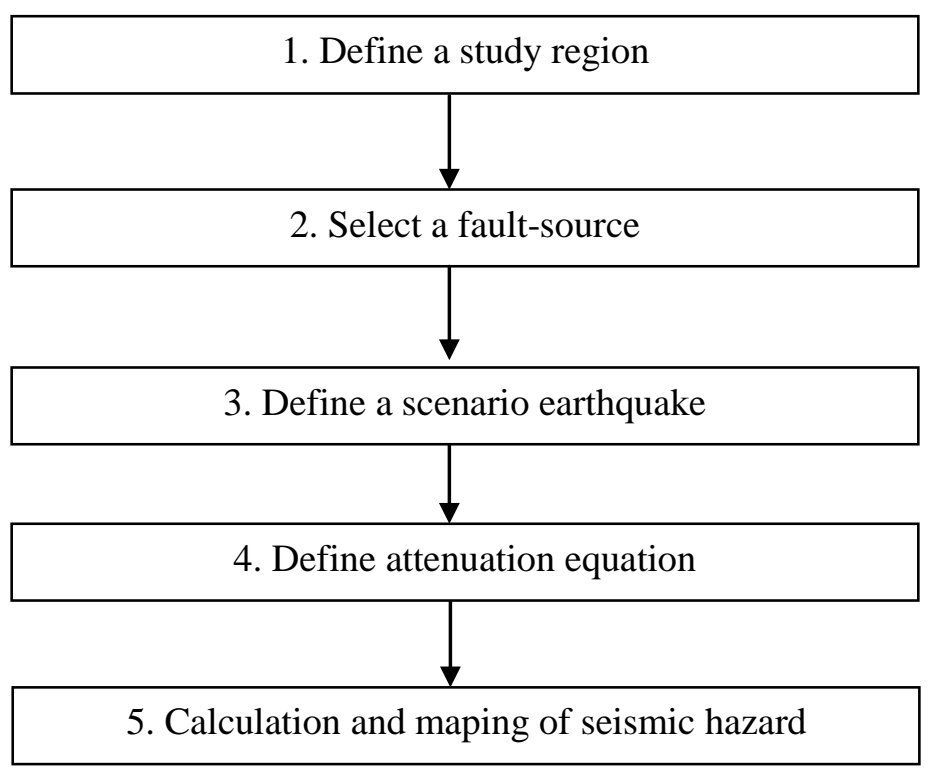

Figure 4. A procedure for scenario-based seismic hazard assessment using the Vietnam’s fault-source model 
Nguyen Hong Phuong, et al./Vietnam Journal of Earth Sciences 40 (2018)

Table 2. Relationship between values PGA and shaking intensity I (MSK-64 scale)

\begin{tabular}{cc}
\hline PGA $(\mathrm{g})$ & Intensity I \\
\hline $0.015-0.03$ & V \\
$0.03-0.06$ & VI \\
$0.06-0.12$ & VII \\
$0.12-0.24$ & VIII \\
$0.24-0.49$ & IX \\
$>0.49$ & $\mathrm{X}$ \\
\hline
\end{tabular}

F-Hazard has been verified and validated through many research studies on seismic hazard assessment in Vietnam. Nevertheless, the desktop GIS environment makes the scope of application of F-Hazard is more or less limited comparing with an internet environment. Besides, F-Hazard was designed with more intention focusing on a seismic hazard assessment tool, but not as an earthquake early warning tool. All above mentioned disadvantages were taken into account in the development of a Web GIS based on-line DSS.

\subsection{Development of a Web-GIS tool: RARE}

Based on the F-Hazard algorithm, an online tool for rapid assessment of seismic hazard from real-time earthquakes (RARE) was developed and integrated into the DSS, using the Web GIS technology. In this case, the Vietnam's fault source model was migrated in the DSS in terms of a map layer showing distribution of all seismically active faults systems in the territory of Vietnam and adjacent sea area (Figure 5). With this layer activated, the user can query all attribute information of each fault source as well as to manipulate the tool.
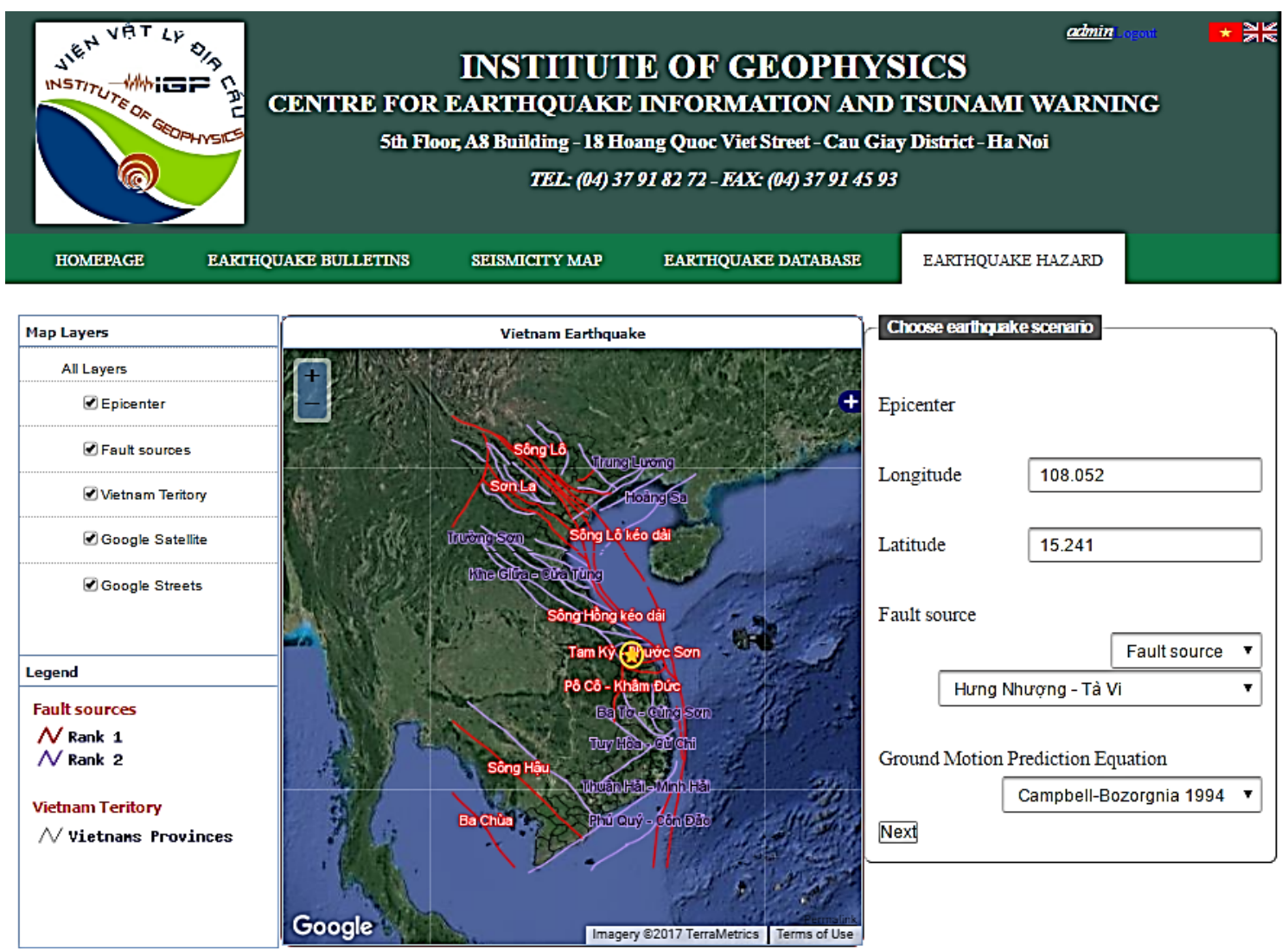

Figure 5. Map of seismically active faults systems in the territory of Vietnam and adjacent sea area in the DSS for on-line earthquake warning 
Results of analyzing the GMPEs most suitable for the Vietnam's conditions lead to the following selection of attenuation models to be used in RARE:

(i) The Campbell and Bozorgnia (1994) attenuation model.

(ii) The Toro, Abrahamson and Shneider (1997) attenuation model.

(iii) The Campbell-Bozorgnia (2008) attenuation model.

(iv) The Bore-Atkinson (2008) attenuation model.

(v) The Chiu-Young (2008) attenuation model.

All of these attenuation models are developed for shallow crust earthquakes and most suitable for the events with moment magnitudes ranging from M5.0 to M8.0. The models 3,4 and 5 were developed recently within the Next Generation Attenuation of Ground Motion (NGA08) project lead by the Pacific Earthquake Engineering Research Center (PEER, 2008). The advantage of these models is that they have been developed using the most complete up to now database of strongmotion records of all over the world.

It should be noted that although the source parameters are assigned automatically from the existing active faults database, the user can always change these values by more suitable ones. For each attenuation model, the input parameters are changeable. To compute ground shaking, the user can select any period in a range from $\mathrm{T}=0.01 \mathrm{~s}$ to $\mathrm{T}=10 \mathrm{~s}$.

\section{Application of RARE for early earth- quake warning in Vietnam}

As RARE has the same function of a scenario-based seismic hazard assessment tool as its prototype, this paper will give an example of using the RARE in an earthquake warning procedure. For illustration, the event recorded on February 26 $6^{\text {th }}, 2017$ in Nam Tra My, Quang Nam province is chosen as a scenario earthquake, with the following parameters determined: (i) Epicenter's coordinates Longitude = 108.052 E; Latitude $=15.241 \mathrm{~N}$;

(ii) Magnitude: $\mathrm{M}_{\mathrm{w}}=3,9$;

(iii) Focal depth: $\mathrm{H}=10 \mathrm{~km}$.

In order to use the RARE, the user needs to access to the "Earthquake Hazard" tab. Here, the whole procedure of scenario earthquake creation, calculation and display the shake map caused by the scenario earthquake is implemented by following the steps described below.

(i) Input the parameters of the scenario earthquake. The "Choose earthquake scenario" window will allow user to input the parameters of the scenario earthquake. There are two options for the user to input the parameters. The first option is to input manually the parameters into the "Longitude" and "Latitude" textboxes of the window. For the second option, from the Earthquake catalog shown in Figure 2, by clicking on "scenario" of the choosen earthquake in the last column on the right, the coordinates of the epicenter of scenario earthquake will automatically appear in the "Choose earthquake scenario" window (Figure 6).

(ii) Selection of seismic source. In the "Fault source" drop-down list of the "Choose earthquake scenario" window, user should opt to choose one of the following types of seismic source:

A point source can be selected when epicenter of the scenario earthquake does not match any fault in the active faults map. In this case, with assumption that earthquake is originated by a tectonic fault, an application called "Building a fault" will be provided to help user define a fault line crossing the epicenter of scenario earthquake, with the source parameters defined by user. Usually parameters of the fault located nearest to the epicenter in the map will be assigned for the newly built fault source. Rupture orientation is measured in degrees (0 to 360) clockwise from North. Rupture length is based on the default magnitude versus rupture length relationship (Wells and Coppersmith, 1994) unless the user chooses to override it. 
Vietnam Journal of Earth Sciences, 40(3), 193-206

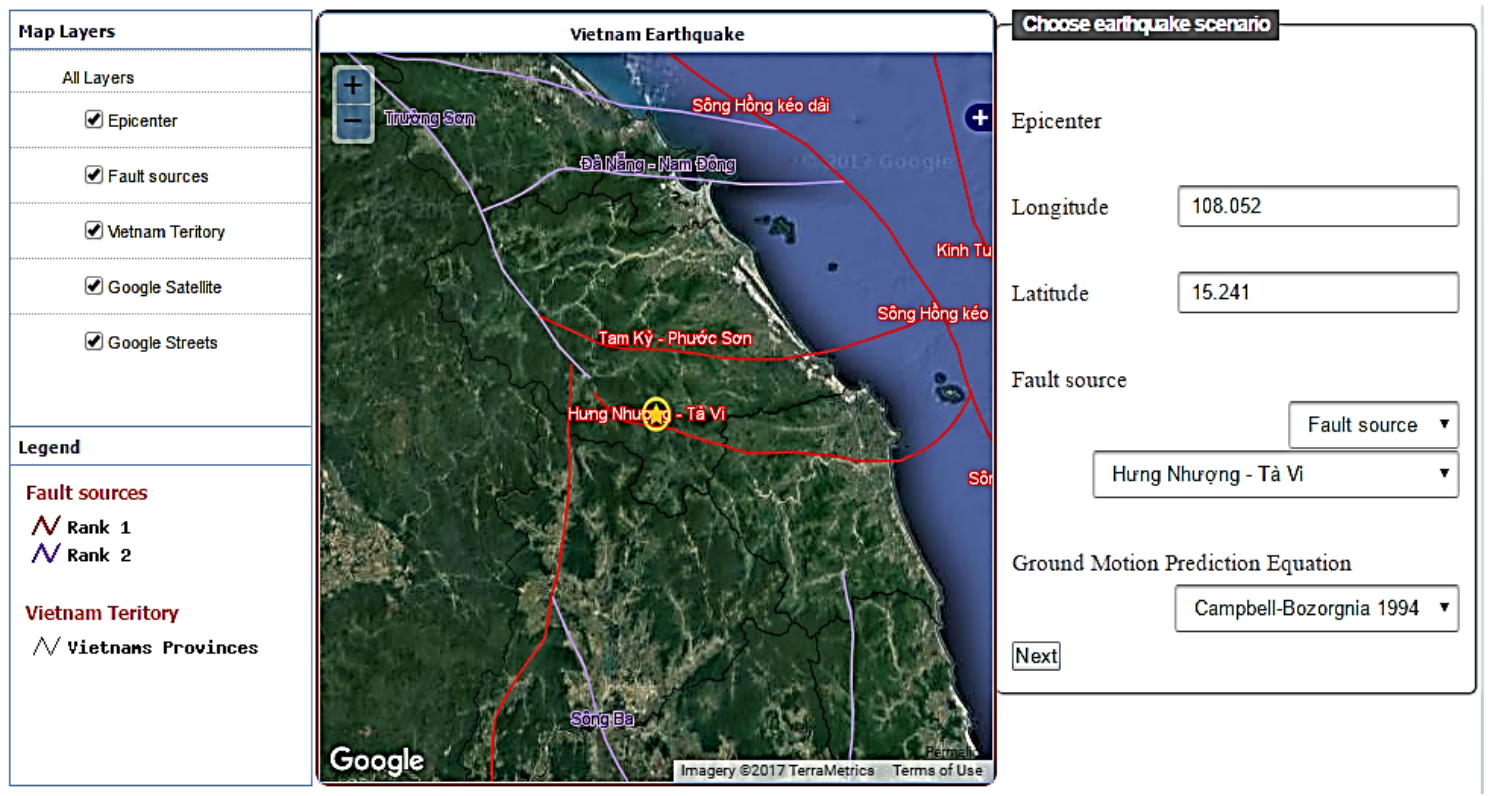

Figure 6. Defining parameters of a scenario earthquake by RARE tool

A fault source can be selected when epicenter of the scenario earthquake coincides with a fault source in the active faults map. In this case, the user needs to activate the layer of active faults by click on the "Fault source" check box on the left side of the map. Then the user can select a fault to define the source for the scenario earthquake simply by clicking on that fault. Usually a fault located nearest to the epicenter of scenario earthquake is chosen to be the source. Once selected, the fault source's color will be changed to distinguish with the rest in the map. The user can also select a fault source from a drop-down list (Figure 7).

For the chosen Nam Tra My scenario, the source selected is Hung Nhuong - Ta Vi fault, of which the geometric and geodynamic parameters were automatically retrieved from the database of active faults systems (Dinh Van Toan et al., 2017).

(iii) Selection of the attenuation models. The "Ground Motion Prediction Equation" drop-down list in the "Choose earthquake scenario" window allows the user to select a suitable attenuation model for the study region (Figure 8). A window will appear to allow updating suitable parameters for the chosen model.

\begin{tabular}{|l|}
\hline Hưng Nhượng - Tà Vi \\
\hline Ba Chùa \\
Ba Tơ - Củng Sơn \\
Buôn Hồ \\
Cẩm Phà - Linh Sơn \\
Cao Bằng - Tiên Yên \\
Cô Tô - Bắc Hài \\
Đà Nắng - Nam Đông \\
Đắkrông - Huế \\
Đông Triều - Uông Bí \\
Hoàng Sa \\
Hưng Nhượng - Tà Vi \\
Khe Bố - Hà Tĩnh \\
Khe Giữa - Cữa Tùng \\
Kinh Tuyến 109 \\
Lai Châu - Điê̂n Biên \\
Mường La - Bắc Yên \\
Nghĩa Lộ - Thanh Sơn \\
Phong Thổ \\
Phu May Tun \\
Phú Quý - Côn Đào \\
\hline
\end{tabular}

Figure 7. Selection of a fault source in RARE 


\section{Campbell-Bozorgnia $1994 \quad$ V \\ Campbell-Bozorgnia 1994 \\ Toro 1997 \\ Campbell-Bozorgnia 2008 \\ Boore-Atkinson 2008 \\ Chiou-Youngs 2008}

Figure 8. Selection of an attenuation model in RARE

(iv) Calculation and display the shake map caused by the scenario earthquake. After going through all above-described steps, the user can click on the "Calculation" button to finish the procedure of hazard scenario definition. The RARE automatically calculates and displays a shake map caused by the scenario earthquake for the study region.

Figure 9 shows a shake map calculated for the chosen Nam Tra My earthquake. The color scale in lower part of the map is applied for both PGA (in g) and Intensity (MSK-64) values. The RARE's spatial analysis tools allow user to querry the ground shaking at any point on the map just by a click. The query information includes the point's coordinates and the corresponding values of PGA and I (MSK-64) at that point.

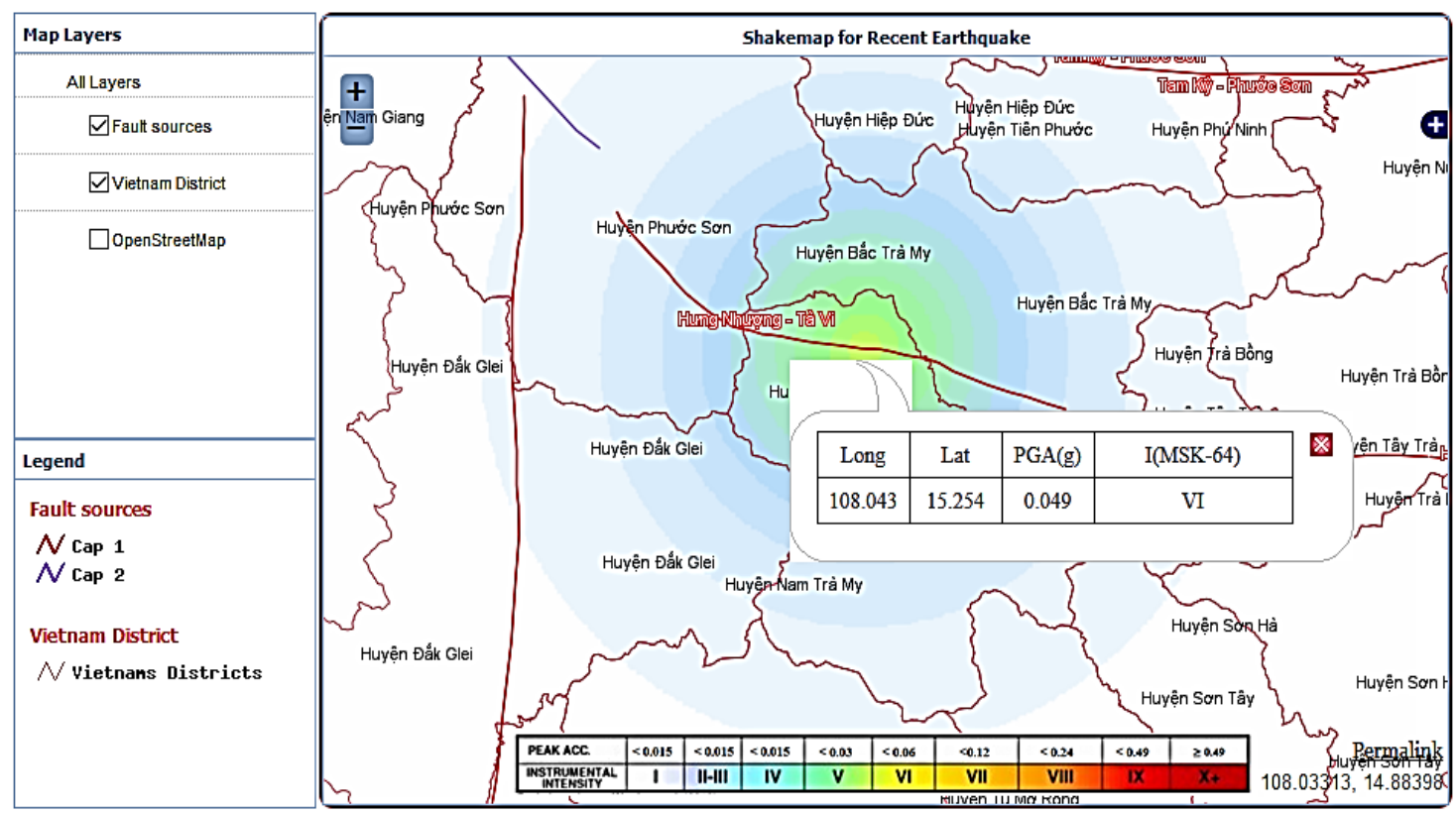

Figure 9. A shake map compiled from the real-time Nam Tra My earthquake using the RARE tool

Beside the function of compiling shake map from a real-time earthquake, some other functions are integrated in the RARE that support the earthquake warning procedure including:

- Create a report on the newly occurred earthquake;

- Send emails to people and organizations of different responsibility and registered clients.
Another application that can be developed within the DSS to support the earthquake warning process is the estimation of the number of people, likely be affected by an earthquake within $0.5^{\circ}(60 \mathrm{~km})$ from the epicentre. As there is no reliable census data available for Vietnam at the moment, the test calculation has been carried out using the shaking maps created by RARE and version 4 of the 
Nguyen Hong Phuong, et al./Vietnam Journal of Earth Sciences 40 (2018)

map of gridded population of the Word (GPW) issued by The A Data Center of NASA (Center for International Earth Science Information Network - CIESIN - Columbia University, 2016).
The final product of the DSS is an earthquake bulletin with the information on earthquake parameters and its possible impacts in the area, affected by the earthquake. A part of the bulletin is illustrated on Figure 10.

\section{Exposure Population}

\begin{tabular}{|l|c|c|c|c|c|c|}
\hline Intensity & V & VI & VII & VIII & IX & X \\
\hline Population & 167456 & 49493 & 0 & 0 & 0 & 0 \\
\hline
\end{tabular}

\begin{tabular}{|c|c|c|c|c|}
\hline Ward & District & Province & PGA & Intensity \\
\hline Phước Thành & Phước Sơn & Quảng Nam & 0.0203 & V \\
Phước Kim & Phước Sơn & Quảng Nam & 0.0151 & V \\
Trà Tập & Nam Trà My & Quảng Nam & 0.0293 & V \\
Trà Mai & Nam Trà My & Quảng Nam & 0.0205 & V \\
Trà Leng & Nam Trà My & Quảng Nam & 0.0375 & VI \\
Trà Dơn & Nam Trà My & Quảng Nam & 0.0409 & VI \\
Trà Cang & Nam Trà My & Quảng Nam & 0.0163 & V \\
Trà Tân & Bắc Trà My & Quảng Nam & 0.0245 & V \\
Trà My & Bắc Trà My & Quảng Nam & 0.0162 & V \\
Trà Giác & Bắc Trà My & Quảng Nam & 0.0205 & V \\
Trà Đốc & Bắc Trà My & Quảng Nam & 0.0195 & V \\
Trà Bui & Bắc Trà My & Quảng Nam & 0.0316 & VI \\
Mường Hoong & Đăk Glei & Kon Tum & 0.0172 & V \\
\hline
\end{tabular}

Figure 10. A part of an earthquake bulletin created by the DSS, showing the exposure population and the areas impacted by the earthquake

\section{Discussions}

While having all properties of a tool for scenario-based seismic hazard assessment, the RARE appear to be much more advantageous comparing with F-Hazard thanks to a number of advances. On the one hand, application of Web GIS technology allows the use of RARE on any computer with internet connection and therefore considerably expands its scope of application. In addition, the most of attenua- tion models used in RARE were updated by recent ground motion prediction equations (GMPEs). On the other hand, in the RARE's algorithm, the input parameters of each earthquake scenario are taken directly from a realtime event, just occurred and recorded by the seismic network and therefore the results calculated by the RARE can be used for early warning purpose. The RARE produces grids of acceleration and intensity amplitudes in real-time display for specific users. The distri- 
bution of shaking in an earthquake, whether is expressed as peak ground acceleration or intensity, provides responding organizations a significant increment of information beyond such parameters as magnitude and epicenter. Real-time ground shaking maps provide an immediate opportunity to assess the scope of an event to determine what areas were subject to the highest risk and probable impacts as well as those that received only weak motions and are likely to be undamaged. These maps will certainly find utility in supporting decision making regarding mobilization of resources, damage assessment and aid to victims.

To some extent, the shaking maps produced by the RARE are comparable with those published on-line by USGS and some other international organizations (Wald, et al., 2003, 2006, Marreiros and Carrilho, 2012, Cauzzi et al., 2014). However, RARE should be regarded as a work in progress. At the moment, the system is still unable to generate the shaking maps derived from instrumental data due to the sparse distribution of the national seismic network of Vietnam. In addition, the automated mechanism to pick input parameters from on-line earthquake database for RARE to produce shaking maps will be the next task in the future.

\section{Conclusions}

This paper describes the development of a DSS for earthquake warning service in Vietnam using Web GIS technology. The system consists of two main components: (1) an on-line database of earthquakes recorded from the national seismic network of Vietnam, and (2) a set of tools for rapid seismic hazard assessment. Using an on-line earthquake database, the system allows creating a shake map caused by a newly recorded earthquake. The results of the DSS will automatically be included in the earthquake bulletins issued national wide by the Earthquake Information and Tsunami Warning Center, Institute of Geophysics.
The DSS developed is the means which help to disseminate the flow of earthquake information to the public in fastest and most efficient way. The DSS has proven to be a useful, descriptive display for rapidly assessing the scope and extent of shaking and potential damage following an earthquake. Maps are made available within several minutes after earthquake occurrence for public and scientific consumption via World Wide Web. The capability of the DSS in fast computing/displaying results and issuing earthquake bulletins in the Internet environment allow not only considerably reduce the data processing time, but widely and quickly disseminate information about an earthquake and its impact to the communities in the affected area. Also, the DSS can be used to produce Scenario Earthquake shaking maps, which provide the basis for pre-earthquake planning and understanding the potential effects of large earthquakes in the future.

Moreover, the advantages of the Web GIS technology over desktop GIS in developing a tool for the RARE not only considerably expand the scope of application of the tool itself, but also lead to a higher level of efficiency in seismic hazard assessment in Vietnam in future. The application of the on-line DSS in earthquake warning service can mitigate the earthquake risk as well as reduce the losses and damages due to earthquakes in Vietnam.

\section{Acknowledgements}

This research has been supported by a grant for the basic research project (No.105.05-2017.10) from National Foundation for Science and Technology Development (Nafosted) of Vietnam to Nguyen Hong Phuong.

\section{References}

Boore D.M., Joyner W.B. and Fumal T.E., 1994. Estimation of Response Spectra and Peak Acceleration from Wester North American earthquakes: an interim report, USGS open file report, 94-127, Menlo Park, California, United States Geological Survey. 
Nguyen Hong Phuong, et al./Vietnam Journal of Earth Sciences 40 (2018)

Boore D.M. and Atkinson G.M., 2008. Ground-Motion Prediction Equations for the Average Horizontal Component of PGA, PGV, and 5\%-Damped PSA at Spectral Periods between $0.01 \mathrm{~s}$ and $10.0 \mathrm{~s}$. Earthquake Spectra, 24(1), 1-341.

Bui Van Duan, Nguyen Anh Duong, 2017. The relation between fault movement potential and seismic activity of major faults in Northwestern Vietnam. Vietnam J. Earth Sci., 39, 240-255.

Campbell K.W. and Bozorgnia Y., 1994. Near-Source Attenuation of Peak Horizontal Acceleration from Worldwide Accelerograms Recorded from 1957 to 1993, Proceedings, Fifth U.S. National Conference on Earthquake Engineering, Chicago, Illinois, July 10-14: V(III), 283-292.

Campbell K.W. and Bozorgnia Y., 2008. NGA Ground Motion Model for the Geometric Mean Horizontal Component of PGA, PGV, PGD and 5\% Damped Linear Elastic Response Spectra for Periods Ranging from 0.01 to 10s. Earthquake Spectra, 24(1), 1-341.

Cauzzi C., Edwards B., Fäh D., Clinton J., Wiemer S., Kastli F., Cua G. and Giardini D., 2014. On the customisation of shakemap for optimised use in Switzerland, 2014. Proceedings of the 2nd European Conference on Earthquake Engineering and Seismology, Istanbul, August 25-29, 1-10.

Center for International Earth Science Information Network - CIESIN - Columbia University, 2016. Documentation for the Gridded Population of the World, Version 4 (GPWv4). Palisades NY: NASA Socioeconomic Data and Applications Center (SEDAC). http://dx.doi.org/10.7927/H4D50JX4 Accessed April 2018.

Chiou B.S.-J. and Youngs R.R., 2008. An NGA Model for the Average Horizontal Component of Peak Ground Motion and Response Spectra. Earthquake Spectra, 24(1), 1-341.

Cornell, C.A., 1968. Engineering seismic risk analysis. Bull. Seis. Soc. Amer., 58(5), 1583-1606.

Der Kiureghian and A. S-H. Ang, 1977. A fault rupture model for seismic risk analysis, Bull. Seim.
Soc. Am., 67(4), 233-241.

Douglas B.M. and Ryall A., 1977. Seismic risk in linear source regions, with application to the San Adreas fault, Bull. Seis. Soc. Amer., 67, 729-754.

Marreiros, C. and Carrilho, F., 2012. The ShakeMap at the Instituto de Meteorologia. The proceedings of the 15th World Conference on Earthquake Engineering, Lisbon, Portugal September 24-28.

Nguyen Le Minh, et al., 2012. The first peak ground motion attenuation relationships for North of Vietnam. Journal of Asian Earth Sciences. Doi: 10.1016/j.jseaes.2011.09.012.

Nguyen Dinh Xuyen and Tran Thi My Thanh, 1999. To find a formula for computing ground acceleration in strong earthquake in Vietnam, J. Sci. of the Earth, 21, 207-213 (in Vietnamese).

Pacific Earthquake Engineering Research Center, 2008. NGA model for average horizontal component of peak ground motion and response spectra. Earthquake Spectra, 24(1), 1-341.

Tran V.H. and Kiyomiya O., 2012. Ground motion attenuation relationship for shallow strike-slip earthquakes in northern Vietnam based on strong motion records from Japan, Vietnam and adjacent regions, Structural Eng./Earthquake Eng., JSCE, 29, 23-39.

Toro G.R., Abrahamson N.A. and Schneider J.F., 1997. Engineering Model of Strong Ground Motions from Earthquakes in the Central and Eastern United States, Seismological Research Letters, January/February.

Wald D.J., Worden B.C., Quitoriano V. and Pankow K.L., 2006. ShakeMap Manual. Technical manual, users guide, and software guide.

Wald D.L., Wald B. Worden and Goltz J., 2003. ShakeMap - a tool for earthquake response. U.S. Geological Survey Fact Sheet 087-03.

Wells D.L. and Coppersmith K.J., 1994. New Empirical Relationships Among Magnitude, Rupture Length, Rupture Width, and Surface Displacement, Bulletin of the Seismological Society of America, 84, 974-1002. 